\title{
Desenvolvimento e avaliação de um jogo digital educacional sobre aspectos socioculturais de países hispano falantes
}

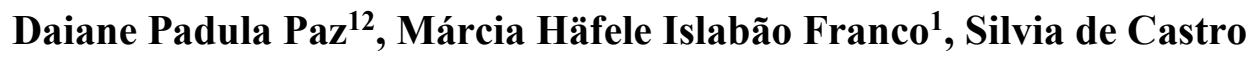 \\ Bertagnolli ${ }^{1}$, Humberto Jorge de Moura Costa ${ }^{3}$ \\ ${ }^{1}$ PPG Mestrado Profissional Informática na Educação, Instituto Federal de Educação, \\ Ciência e Tecnologia do Rio Grande do Sul - Campus Porto Alegre - RS/Brasil \\ ${ }^{2}$ Instituto Federal do Paraná - Campus Palmas - PR/Brasil \\ Instituto Federal de Educação, Ciência e Tecnologia do Rio Grande do Sul - Campus \\ Veranópolis - RS/Brasil

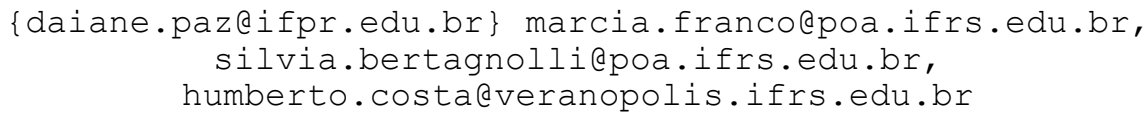

\begin{abstract}
Considering the potential of digital educational games and the need for a differentiated resource for the development of the intercultural competence of Spanish-speaking learners, this research presents the educational digital game El Mochilero, developed as a proposal for an interactive, playful and motivational teaching that which alia Informatics in education in a hybrid teaching proposal. It also presents game evaluation procedures and results obtained, which denote that the software was considered successful for its purposes.
\end{abstract}

Resumo. Considerando-se as potencialidades dos jogos digitais educacionais e a necessidade de um recurso diferenciado para o desenvolvimento da competência intercultural de aprendizes de língua espanhola, esta pesquisa apresenta o jogo digital educacional El Mochilero, desenvolvido como proposta para um ensino interativo, lúdico e motivador que que alia Informática na educação em uma proposta de ensino híbrido. Apresenta também procedimentos de avaliação do jogo e resultados obtidos, os quais denotam que o software foi considerado exitoso para seus fins.

\section{Introdução}

Com a expansão da Informática na Educação muitas coisas mudaram no processo de ensino e aprendizagem, entre elas a abordagem e a disponibilidade de recursos diversificados. Também com a introdução de tecnologias digitais em sala de aula, desenvolveu-se, de forma mais ampla, estratégias de ensino, entre elas o ensino híbrido [Bacich et al. 2015] que consiste em mesclar ensino on e off-line, colocando o aluno em foco no processo de ensino para promover uma aprendizagem mais ativa e autônoma.

Nos últimos anos aumentou de maneira exponencial a disponibilidade de jogos digitais educacionais; os quais têm sido utilizados como importante ferramenta no processo de aquisição do conhecimento, servindo como estratégia de aprendizagem nas 
VII Congresso Brasileiro de Informática na Educação (CBIE 2018)

Anais do XXIX Simpósio Brasileiro de Informática na Educação (SBIE 2018)

mais diversas áreas e níveis de ensino, especialmente por envolverem diversos fatores positivos, cognitivos, culturais, sociais e afetivos [Mattar 2010].

Ao aprender uma língua estrangeira é essencial conhecer também os aspectos socioculturais dos países que a possuem como oficial, para desenvolver a competência intercultural. Considerando-se as potencialidades dos jogos digitais educacionais (JDE) e a necessidade de um recurso diferenciado para o desenvolvimento da competência intercultural de aprendizes de língua espanhola (LE), esta pesquisa propõe o JDE El Mochilero, desenvolvido a partir dos níveis de referência da dimensão cultural do Plano Curricular do Instituto Cervantes (PCIC) e bases do Marco Comum Europeu de Referência (MCER) para um ensino interativo, lúdico e motivador em uma proposta de ensino híbrido. Dessa forma, a relevância acadêmica deste trabalho se constitui não só pelo fato de considerar o emergente fenômeno de JDEs e seus benefícios, mas também por desenvolver uma proposta diferenciada para aprendizagem de aspectos pouco evidenciados nas aulas de línguas: a competência intercultural.

Este artigo está organizado em cinco seções, a saber: Introdução; Contexto, materiais e métodos, que aborda a motivação para este estudo e o estado da arte; Referencial Teórico, que trata sobre aspectos relevantes que embasam esta pesquisa com relação a jogos e aprendizagem e competência intercultural; Jogo El Mochilero, seção que apresenta o software proposto, Avaliação do jogo, que apresenta os procedimentos utilizados para validação e avaliação do produto educacional e, por fim, a seção Resultados, que descreve principais resultados obtidos nas avaliações realizadas, os quais denotaram grande interesse e efetividade de aprendizado por parte dos usuários.

\section{Contexto, materiais e métodos}

O contexto desta pesquisa parte da hipótese de que o uso de jogos no processo educacional proporciona motivação ao estudante, considerando também o valor da dimensão cultural para aprendizes de LE e que é possível aprender sobre aspectos socioculturais de forma diferenciada e lúdica.

Para tanto, fez-se necessário realizar diversos procedimentos que compõe a metodologia desta pesquisa, começando por uma refinada pesquisa bibliográfica sobre as temáticas envolvidas e teorias relacionadas ao uso de jogos, como a da Aprendizagem significativa, de David Ausubel (2003), Aprendizagem baseada em jogos digitais, de Marc Prensky (2012) e Ensino híbrido [Bacich et al. 2015]. Logo, pesquisou-se sobre características e tipologia de JDs e buscou-se conhecer o estado da arte de jogos com enfoque intercultural, percebendo-se, então, uma lacuna na área, devido à indisponibilidade desse tipo de jogos, sobretudo em LE. Na sequência foram estudados documentos norteadores para o desenvolvimento da referida competência, os quais serviram de referência para a produção do software educacional El Mochilero.

Para a definição de critérios e características do produto educacional proposto, realizou-se, inicialmente, uma busca por jogos (aplicativos) com temáticas relacionadas à cultura de países hispânicos. Para tanto, pesquisou-se, nas lojas App Store, para plataforma iOS, e Google Play, para plataforma Android, algumas palavras-chave, tais como "cultura hispânica", "Cultura hispana", "Hispanic culture. Não foram encontrados aplicativos com fins específicos para o desenvolvimento da competência intercultural em LE, então, buscou-se por outros com características correlatas de interessa da pesquisa: aplicativos para ensino de idiomas, aplicativos do tipo Quiz e aplicativos que tratem de alguma forma aspectos culturais relacionados ao mundo hispânico. 
VII Congresso Brasileiro de Informática na Educação (CBIE 2018)

Anais do XXIX Simpósio Brasileiro de Informática na Educação (SBIE 2018)

Feita a pesquisa, selecionou-se aplicativos bem avaliados nas lojas e de conhecimento popular. Assim, foram escolhidos dois aplicativos em cada categoria: i) Duolingo e Busuu, na categoria ensino de idiomas; ii) Perguntados e Quizup, como jogos de trivia/quiz; iii) Un viaje por América del Sur e Eye Spain, como aplicativos que tratem de temáticas de culturais hispânicas. A partir desse levantamento, elaborou-se uma matriz comparativa, com o intuito de identificar as características, potencialidades e lacunas dos softwares disponíveis para implementação ou não no jogo proposto.

Ainda, foram estudados os procedimentos de desenvolvimento de JDs, abrangendo os períodos de pré-produção, produção e pós-produção, de modo que o produto fosse bem elaborado e que houvesse registros formais desde a fase de prototipagem até a etapa de divulgação. Nesta etapa elaborou-se também um projeto pedagógico sobre os países hispanofalantes, denominado "Cultura en la Mochila".

Durante o desenvolvimento do software buscou-se modelos de avaliação para JDEs e, selecionou-se modelo MEEGA+ [Savi 2011] por considerá-lo bastante abrangente. Visando obter dados específicos para este estudo realizou-se pequenas adaptações ao modelo proposto. de modo a complementá-lo. Após a disponibilização do jogo El Mochilero, realizou-se sua avaliação com estudantes através de um Questionário de avaliação e Análise de desempenho, possibilitando a coleta de dados para uma análise quantitativa e descritiva, considerando suas potencialidades e sua validação como recurso estratégico para o desenvolvimento da competência intercultural dos aprendizes de LE.

Em suma, esta pesquisa se desenvolve em diversas etapas, muitas destas realizadas simultaneamente, a saber: composição da fundamentação teórica; definição de diretrizes e busca de trabalhos relacionados; desenvolvimento do software, elaboração e aplicação do projeto de ensino híbrido; aplicação e avaliação do JD; avaliação do projeto com sujeitos envolvidos; e, por fim, compilação e análise de dados coletados. Todos os procedimentos foram devidamente registrados, compondo as diversas seções desta pesquisa e importante material de referência.

\section{Referencial Teórico}

Esta pesquisa, com enfoque de implementação de Informática na Educação, detém-se em teorias que se relacionam de forma integrada nesta área de conhecimento. Para tanto, delimitou-se linhas de referência para o embasamento da proposta de cunho pedagógico e, sobretudo, para uma orientação pautada em temas relevantes e atuais.

\subsection{Jogos e Aprendizagem}

Quando elaborados para fins educacionais, os jogos podem ser denominados como jogos educacionais ou educativos, jogos de aprendizagem ou jogos sérios [Savi 2008]. Embora haja discussões quanto a definição de jogo educacional, o que é certo é que podem ser definidos como educacionais quando são motivadores do processo de aprendizagem [Tarouco 2004). Estes podem apresentar muitas vantagens, como: o desenvolvimento de habilidades cognitivas [Gros 2006]; melhorar a capacidade de trabalho em grupo [Mattar 2010], permitem o reconhecimento e entendimento de regras [Tarouco 2004] além de contribuir positivamente na aprendizagem [Wangenheim, Kochanski, Savi 2009]. 
VII Congresso Brasileiro de Informática na Educação (CBIE 2018)

Anais do XXIX Simpósio Brasileiro de Informática na Educação (SBIE 2018)

A partir da utilização de jogos educacionais, pode-se promover a Aprendizagem Baseada em Jogos Digitais [Battistela 2016], defendida por Prensky (2012) ao afirmar que esta abordagem funciona pelas seguintes razões: a) há um envolvimento, devido ao fato da aprendizagem ser colocada em um contexto; b) há um processo interativo da aprendizagem, que pode assumir diferentes formas; c) a maneira como são unidos - o envolvimento e o processo interativo - é altamente contextual. Considerando tais aspectos agregados às linhas teóricas que abordam metodologias ativas e o ensino híbrido [Horn e Staker 2015] optou-se por considerar o valor que esta proposta pode significar em estudos da área.

\subsection{Competência intercultural}

O eixo central desta pesquisa está no desenvolvimento da competência intercultural, que considera o agir e respeitar a cultura alheia,

sob o prisma de que língua e cultura andam juntas no processo de aprendizagem [Bravo-García 2015]. Assim, este estudo baseou-se nas três seções da dimensão cultural do PCIC (2006) para a elaboração das questões (Quiz) do jogo desenvolvido, denominadas: Referentes culturais, Saberes e comportamentos e socioculturais e Habilidades e atitudes interculturais.

Embora não haja no referencial teórico uma determinação sobre parâmetros de aferição da competência intercultural, pode-se considera-la através da percepção de valores da diversidade de manifestações culturais, sendo neste caso, em relação à cultura de origem hispânica que compõe a cultura dos 21 países que possuem o espanhol como língua oficial. O referido jogo, em sua proposta, apresenta elementos diversos da cultura destes países para disseminação do conhecimento em uma perspectiva de alteridade. Assim, as avaliações sobre o desenvolvimento da competência intercultural após o uso do jogo consideraram essa tomada de consciência por parte dos estudantes-usuários.

\section{Jogo Digital Educacional El Mochilero}

O jogo El Mochilero está desenhado como ferramenta complementar para o desenvolvimento da competência intercultural de aprendizes de língua espanhola, sob uma perspectiva de ensino e aprendizagem de valores, habilidades, atitudes e conhecimentos essenciais para despertar uma consciência de identificação étnica e respeito à multiculturalidade. Para tanto, o jogo baseia-se em dois importantes documentos que norteiam o ensino do espanhol no mundo, já mencionados: o PCIC (2006) e o MCER (2002).

Cabe destacar que este jogo não tem por finalidade o ensino de conteúdos gramaticais de LE, nem o desenvolvimento de habilidades específicas que promovam fluência no idioma, entretanto, está desenvolvido totalmente em espanhol pelos seguintes motivos: i) há uma mínima oferta de jogos em língua espanhola, ii) a integração do idioma com a temática cultural torna a proposta mais coerente; iii) poderá proporcionar, mesmo de forma indireta, novos conhecimentos na língua meta.

Para o desenvolvimento de um jogo é preciso pensar três etapas principais: préprodução, produção e pós-produção [Mattar 2010]. Na primeira etapa, realizou-se a conceituação, o game design document e o planejamento de produção e arte; na segunda, o protótipo e a implementação; e na terceira etapa, foram realizados testes, disponibilização e divulgação do jogo e plano de arquivamento. Todas as etapas foram 
VII Congresso Brasileiro de Informática na Educação (CBIE 2018)

Anais do XXIX Simpósio Brasileiro de Informática na Educação (SBIE 2018)

registradas, compondo relevante seção da pesquisa, sobretudo, para servir como fonte de consulta para a elaboração de versões posteriores do software.

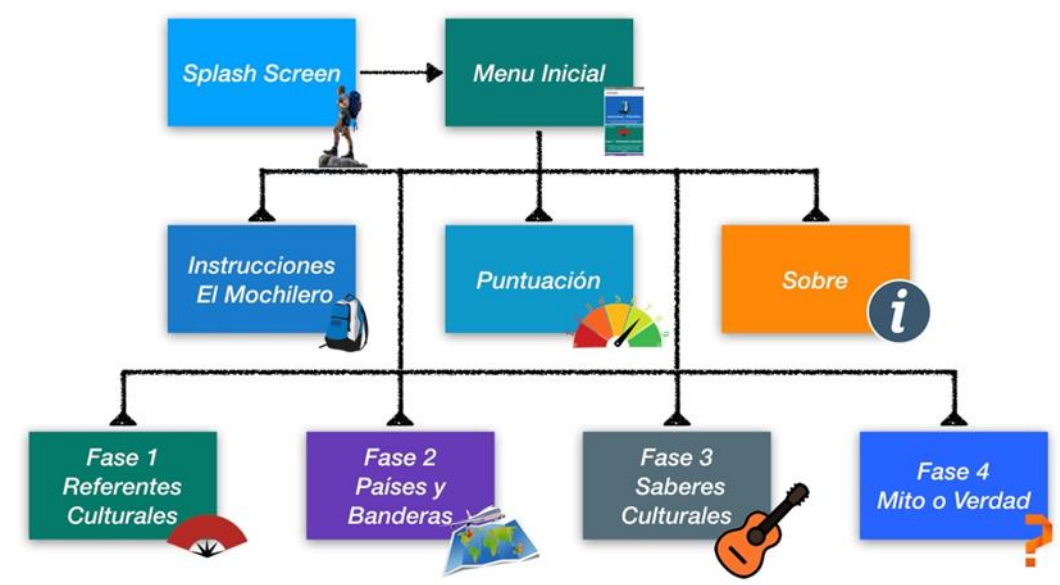

Figura 1 - Fluxo do jogo

Desenvolvido totalmente em espanhol, o referido jogo sério apresenta um personagem viajante - El Mochilero - que está conhecendo países hispanofalantes e necessita conseguir moedas para prosseguir sua viagem, portanto o jogador deverá ajudá-lo respondendo às questões do quiz em cada uma das quatro fases, elaboradas a partir das seções: Referentes culturais, Saberes e comportamentos socioculturais e Habilidades e atitudes interculturais, as quais dão nome às fases 1 e 3 do jogo. Ainda, foi acrescentada uma quarta fase, denominada "Mito o verdad", a qual, com uma estrutura diferente faz uma revisão sobre os aspectos das fases anteriores.

A cada acerto o jogador recebe 100 (cem) pontos e avança para a questão seguinte. Esperando obter um desempenho satisfatório, a fase seguinte só será desbloqueada ao acertar, no mínimo, 50\% das questões do quiz (Figura 2). Com finalidade de aprendizado, o usuário poderá retomar o jogo quantas vezes quiser e sempre será salvo seu maior desempenho no placar final de cada fase.

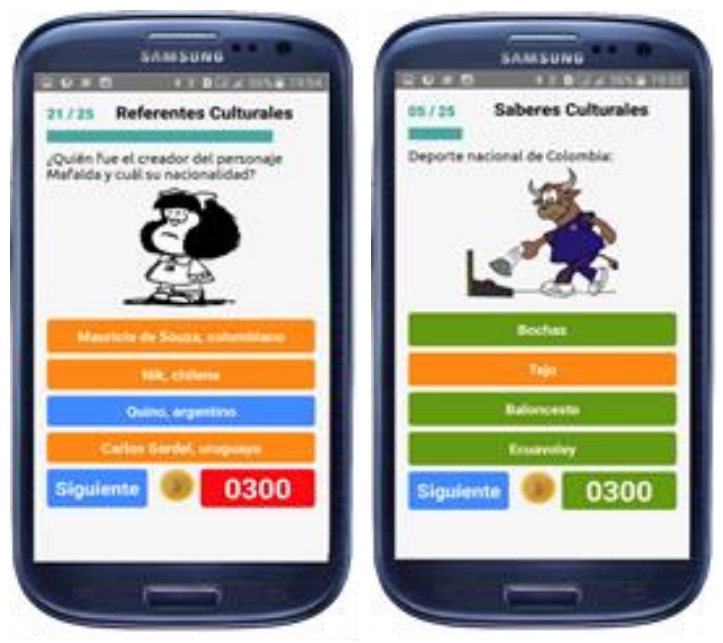

Figura 2: Telas do jogo

Para facilitar a difusão e download do jogo optou-se por disponibilizá-lo, de forma gratuita, na loja de aplicativos Google Play, na categoria de apps de Educação. Espera-se, dessa forma, que estudantes, ao pesquisarem por aplicativos relacionados a 
VII Congresso Brasileiro de Informática na Educação (CBIE 2018)

Anais do XXIX Simpósio Brasileiro de Informática na Educação (SBIE 2018)

cultura hispânica, encontrem o El Mochilero como uma opção de aprendizado e possam avaliá-lo.

\section{Avaliação do jogo}

Para que sejam considerados jogos educacionais, é preciso que estes tenham objetivos de aprendizagem bem definidos e ensinem conteúdos aos usuários, ou então, que promovam o desenvolvimento de estratégias ou habilidades para ampliar a capacidade cognitiva e intelectual dos alunos [Gros 2003]. Nos últimos anos, muitos jogos digitais têm sido desenvolvidos para colaborar no processo de ensino e aprendizagem, entretanto, é necessário que sua(s) funcionalidade(s) e eficácia sejam avaliadas de forma satisfatória.

Com o propósito de realizar uma avaliação do jogo El Mochilero quanto a sua contribuição no ensino, fez-se necessário buscar na literatura recente, modelos de avaliação de jogos, para então selecionar o mais adequado, considerando dois importantes aspectos: i) avaliação do jogo considerando suas características como design, jogabilidade e experiência do usuário; ii) avaliação do aprendizado referente aos objetivos da proposta (desenvolvimento da competência intercultural). Assim, para a avaliação optou-se pelo modelo MEEGA+ [Savi 2011] por considerá-lo bastante abrangente, entretanto, para coletar dados mais específicos, realizou-se adaptações.

Antes da avaliação com as turmas selecionadas, realizou-se o Playtest para obter feedback relativo a problemas de design. Após, realizou-se a avaliação do jogo $E l$ Mochilero visando obter dados essenciais para a pesquisa. Esta etapa realizou-se sob duas perspectivas: a primeira, a partir de um questionário estruturado, da versão adaptada do modelo MEEGA+; a segunda, a partir do levantamento de dados de desempenho (pontuação) dos estudantes em cada rodada que jogaram o JD. Cabe ressaltar que se observou também de forma periódica, o interesse e engajamento dos estudantes em relação à temática e o desejo de jogar.

\section{Resultados}

Qualquer tipo de procedimento sério de avaliação implica em coleta de dados. Estes precisam ser organizados, analisados, interpretados e comunicados adequadamente [Savi 2011]. Muitos dados foram obtidos a partir do Questionário de Avaliação (QA) do jogo e da Avaliação de Desempenho (AD), aplicados em duas turmas do Ensino Médio do Instituto Federal do Paraná, Campus Palmas.

O QA foi respondido por um total de 46 estudantes após o uso do jogo em aulas de língua espanhola. Para melhor análise dos resultados, considerou-se os itens de cada um dos blocos sendo, respectivamente: Dados demográficos; Experiência do jogador; Estrutura do jogo; Percepção da aprendizagem; Competência intercultural e Comentários. Muitos dados importantes foram obtidos através do QA, entretanto, neste artigo, apresentam-se apenas os essenciais com enfoque na experiência do jogador, sua percepção sobre a aprendizagem e sobre o desenvolvimento da competência intercultural.

A seção "Experiência do jogador" contém um total de 30 questões referentes à usabilidade, confiança, desafio, satisfação, interação, diversão, atenção e relevância. Mensurando-se em percentual, os resultados obtidos nessa seção denotam que a ampla maioria dos usuários avaliou sua experiência como positiva, em todos os aspectos, especialmente relevância e satisfação (Figura 3). 
VII Congresso Brasileiro de Informática na Educação (CBIE 2018)

Anais do XXIX Simpósio Brasileiro de Informática na Educação (SBIE 2018)

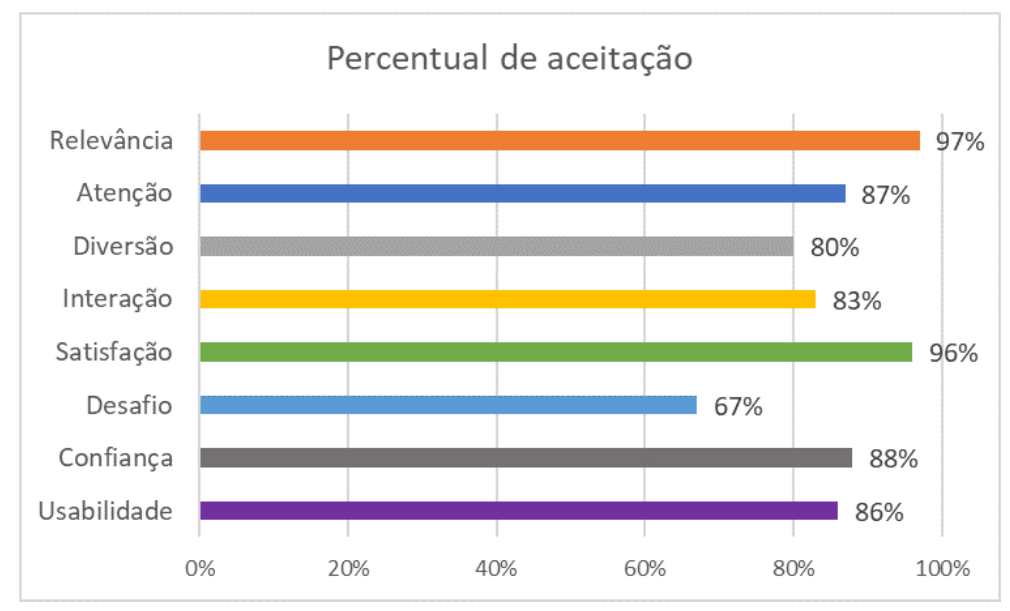

Figura 3: Percentual de aceitação Experiência do jogador

A categoria "Desafio" apresentou menor índice de aceitação (67\%), houve indicação de que o jogo se tornava monótono nas etapas por repetir questões no quiz. Isso ocorreu pelo fato de que a versão de teste (protótipo do aplicativo) apresenta um banco de questões ainda limitado. Cabe destacar que a codificação do jogo foi concebida para suportar o acréscimo de novas perguntas e fases, bastando inseri-las no banco de questões, e que esta melhoria já está sendo executada para uma nova versão.

$\mathrm{Na}$ categoria "Interação" constatou-se que houve incidência de estudantes que indicaram que o jogo não proporciona interação entre os jogadores pois em sua percepção, interação se dá através da modalidade multiplayer. Embora haja um ranking automático elaborado pelo Google Play Games que está integrado no jogo, é fato que a interação com outros usuários pode ser melhor explorada e neste sentido, está sendo desenvolvida a opção desafio para que o usuário possa convidar alguém para jogar, ou mesmo pela opção oponente aleatório.

No QA, a seção "Percepção da aprendizagem" está composta por doze questões que buscam coletar dados sobre as contribuições do jogo El Mochilero como recurso educacional e para avaliar se seus objetivos foram atingidos. Para mensuração de dados deste modelo adaptado do MEEGA+, as respostas apresentam escala Likert de indicação gradual - Discordo fortemente, Discordo, Indiferente, Concordo, Concordo fortemente - e os resultados indicam ainda a mediana, sistema de medida comumente utilizada em estatística para indicar o valor central de um conjunto de valores.

Percebe-se que na maioria dos itens considerados na QA, os usuários indicam concordar fortemente com as afirmativas (Figura 4). Este resultado positivo converge à indicação deste software como importante recurso para o ensino de aspectos relacionados à cultura hispânica e, por conseguinte, desenvolvimento da competência sociocultural dos usuários. 
VII Congresso Brasileiro de Informática na Educação (CBIE 2018)

Anais do XXIX Simpósio Brasileiro de Informática na Educação (SBIE 2018)

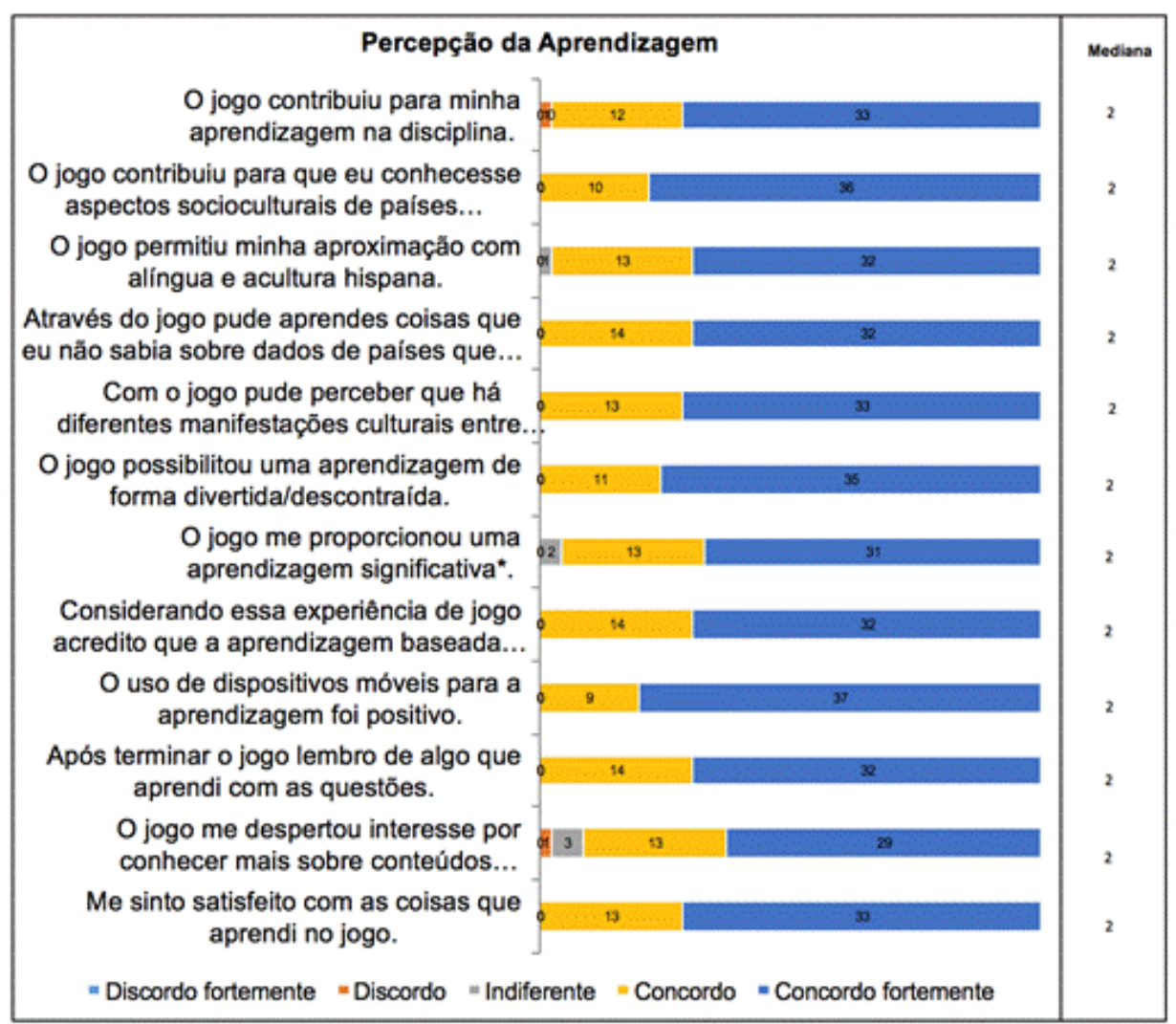

Figura 4: Dados Percepção da aprendizagem

$\mathrm{Na}$ seção "Competência intercultural" (Figura 5), percebe-se a ampla concordância de que o jogo colabora com o desenvolvimento da competência intercultural, fato de extrema relevância para os resultados desse trabalho. Considerando o conjunto de resultados dessa categoria e da categoria de percepção da aprendizagem, pode-se afirmar que houve êxito na proposta de implementação de um jogo digital educacional para o desenvolvimento da competência intercultural e que, nestas condições, o jogo elaborado atende a maioria dos quesitos de forma totalmente satisfatória, resultando ser uma significante e inovadora alternativa para esse fim.

Para visualização global dos resultados, além dos gráficos gerados pelo sistema MEEGA+, realizou-se o índice do percentual de aceitação geral de cada uma das quatro seções, tendo $85 \%$ de aceitação na seção experiência do jogador, $70 \%$ da estrutura do jogo, $99 \%$ da percepção da aprendizagem e 93\% da competência intercultural., Os resultados globais confirmam um alto percentual de aceitação na totalidade, representando quase unanimidade de opinião entre os usuários do jogo. 
VII Congresso Brasileiro de Informática na Educação (CBIE 2018)

Anais do XXIX Simpósio Brasileiro de Informática na Educação (SBIE 2018)

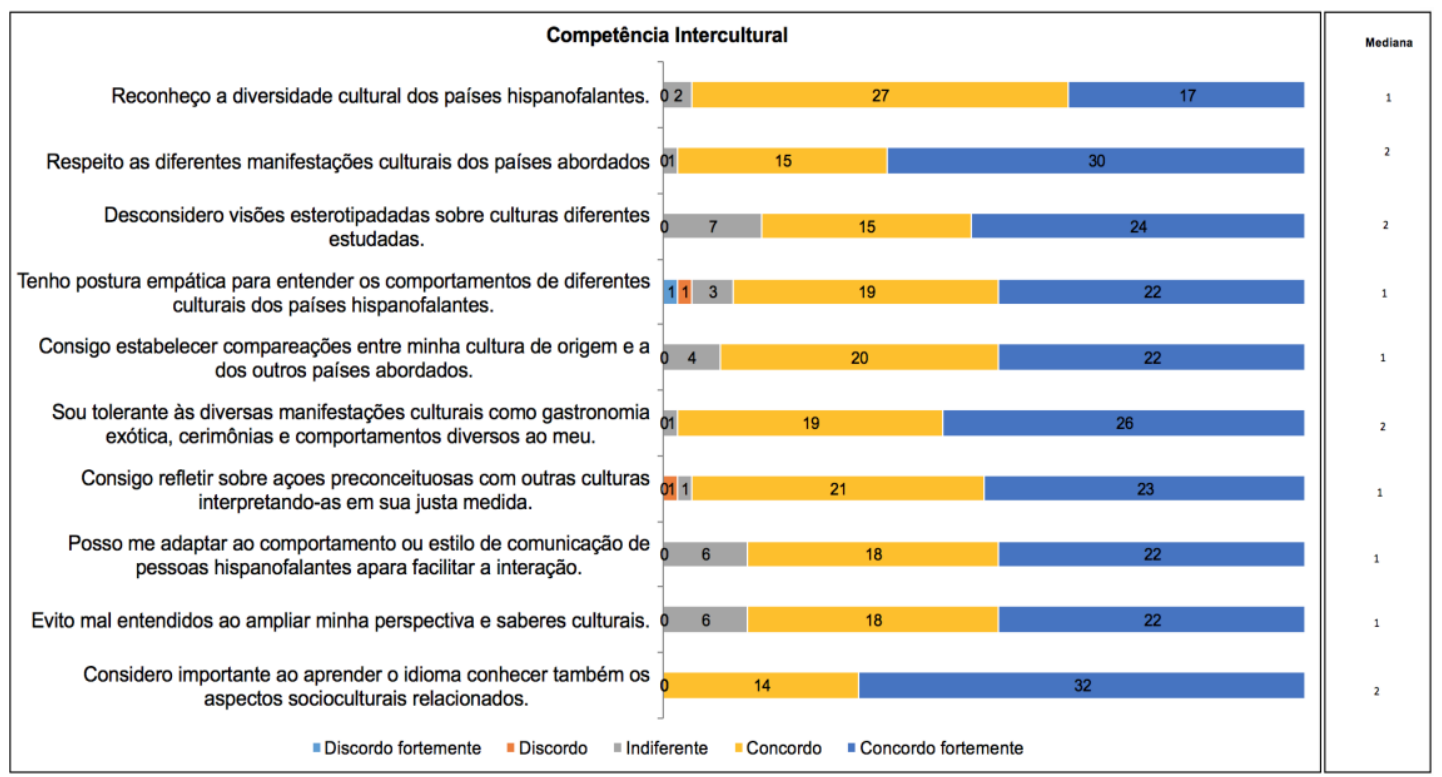

Figura 5: Dados Competência Intercultural

O outro viés da avaliação foi realizado através da Avaliação de Desempenho dos jogadores, com o objetivo de verificar se, a cada jogada, seriam capazes de obter melhores rendimentos, dados estes auferidos pela pontuação final (acertos) em cada fase. Para tanto, foram realizadas, em sala de aula, quatro rodadas incluindo todas as fases do jogo. Para realizar a análise comparativa deve-se considerar que as fases 1 e 3, denominadas Referentes Culturales e Saberes Culturales respectivamente, possuem um total de 25 questões (amostra) de 50 possíveis (população), enquanto na fase 2 , denominada Países y banderas, totaliza 15 questões, de 21 possíveis. Na última fase, ¿mito o verdad?, são sorteadas 15 questões, de 30 possíveis.

Para compilação dos dados coletados foi utilizada uma análise de estatística descritiva, considerando as variáveis quantitativas de número de acertos de questões. Também foram utilizados, neste estudo, algumas medidas de tendência central, como a moda, mediana e a média aritmética. Efetuada por 43 participantes das mesmas turmas, a $\mathrm{AD}$ demonstrou que houve incremento da média aritmética, indicando que, em todas as fases, a maioria dos jogadores evoluíram no desempenho individual. Este fato denota que, possivelmente, ao jogar de forma recorrente, as informações podem ser retidas, gerando conhecimento sobre os aspectos abordados em cada fase. Os dados demonstraram também que os usuários se sentiram expostos à dados sobre cultura hispânica de diversos países, ampliando seus conhecimentos gerais e desenvolvendo, sua competência intercultural à medida que compreendem e valorizam manifestações culturais alheias à sua.

\section{Conclusão}

Este artigo apresentou a proposta de um jogo digital educacional, El Mochilero, elaborado com a finalidade de desenvolver a competência intercultural de aprendizes de língua espanhola e disseminação de aspectos socioculturais de países hispano falantes. Para tanto, apresenta a importância dos jogos como recurso educacional para o processo de ensino e aprendizagem e o valor do estudo da dimensão cultural relacionado ao estudo de línguas, neste caso, com ênfase em língua e cultura de origem hispânica. 
VII Congresso Brasileiro de Informática na Educação (CBIE 2018)

Anais do XXIX Simpósio Brasileiro de Informática na Educação (SBIE 2018)

Este estudo apresenta também o produto educacional desenvolvido e os procedimentos de avaliação aplicados em turmas de Ensino Médio que fizeram uso do jogo em prática de sala de aula. Os resultados do Questionário de Avaliação e da Avaliação de Desempenho demostraram que o aplicativo foi bem aceito e apresenta importante potencial para a motivação da aprendizagem e desenvolvimento da competência intercultural em língua espanhola, objetivo a que se propõe. Assim, esta pesquisa contribui não apenas por desenvolver um software educacional com propósito não encontrado em outros, mas também por apresentar uma proposta que integra Informática na Educação com o objetivo de promover e valorizar práticas pedagógicas inovadoras e experiências exitosas.

\section{References}

Ausubel, D. P (2003) Aquisição e Retenção do Conhecimento: Uma perspectiva cognitiva. Trad. Lígia Teopisto. Lisboa: Plátano.

Bacich, L.; Neto, A., Trevisani, F. M. (2015) Ensino híbrido: personalização e tecnologia na educação. Penso Editora.

Battistella, P. (2016) ENgAGED: Um processo de desenvolvimento de jogos para ensino em computação. Tese. PPGCC, UFSC.

Bravo-García, E. (2015) América en la clase de español: del contenido cultural al psycofact. In: MarcoELE, Madrid, n.21, 2015.

Cervantes, Instituto (2006). "Plan Curricular del Instituto Cervantes". Madri.

Consejo de Europa. (2002) "Marco común europeo de referencia para las lenguas": aprendizaje, enseñanza, evaluación. Madrid.

Gros, B. (2003). The impact of digital games in education. First Monday, v.8, n.7.

Gros, B. (2006). Juegos Digitales para comprender los sistemas complejos.In: Grup F9: Videojocs a l'Aula Revista Comunicación y Pedagogía, n.216.

Horn, M.; Steaker, H. (2015). Blended: usando a inovação disruptiva para aprimorar a educação. Porto Alegre: Penso.

Mattar, J.(2010) Games em educação: como os nativos digitais aprendem. São Paulo: Pearson Prentice Hall.

Prensky, M. (2012) Aprendizagem baseada em jogos digitais. Tradução Eric Yamagute. São Paulo: Senac.

Savi, R. (2011) Avaliação de jogos voltados para a disseminação de conhecimentos. Tese. UFSC, Florianópolis.

Savi, R.; Ulbricht, V. R. (2008) Jogos digitais educacionais: benefícios e desafios. In: Renote: Revista novas tecnologias na educação, v. 6, n. 1.

Tarouco, L. M. (2004) et al. Jogos educacionais. In: Renote: Revista novas tecnologias na educação. Porto Alegre.

Wangenheim, C., Kochanski, D.; Savi, R. (2009) Revisão Sistemática sobre Avaliação de Jogos voltados para Aprendizagem de Engenharia de Software no Brasil. In: XXIII Simpósio Brasileiro de Engenharia de Software, Fortaleza. 